\title{
Temperature and pressure corrections applied to rock thermal conductivity: impact on subsurface temperature prognosis and heat-flow determination in geothermal exploration
}

\author{
Ben Norden * (1), Andrea Förster, Hans-Jürgen Förster and Sven Fuchs
}

\author{
${ }^{*}$ Correspondence: \\ ben.norden@gfz-potsdam.de \\ GFZ German Research \\ Centre for Geosciences, \\ Telegrafenberg, \\ 14473 Potsdam, Germany
}

\begin{abstract}
Precise knowledge of the subsurface thermal field plays a key role in the assessment of geothermal targets. Unfortunately, deep underground temperature data is generally scarce and a matter of research. To achieve first estimates for subsurface temperatures, steady-state conductive thermal modeling is commonly applied. Thereby the rock thermal conductivity is an essential parameter, which is usually determined under ambient laboratory conditions. To arrive with in situ thermal conductivity, the ambient values need to be corrected for in situ temperature and pressure. In this paper, we apply different conversion functions for the correction of thermal conductivity and study the impact on the resultant temperature and heat flow prognoses for a synthetic, upper crustal sedimentary and a magmatic scenario along 2-D geological cross sections. Application of the correction functions results in maximum temperature prognosis uncertainties of about $8{ }^{\circ} \mathrm{C}$ and $55^{\circ} \mathrm{C}$ at $2 \mathrm{~km}$ depth and at $8 \mathrm{~km}$ depth, respectively. The effect positively correlates with the magnitude of the basal heat flow used in modeling. In contrast to the heat flow determined at depth, the resulting surface heat flow is only minor affected by the different correction functions applied. In addition, the modeled temperature at depth is strongly dependent on the type and sequence of application of the pressure and temperature correction equations.
\end{abstract}

Keywords: Subsurface temperature, Thermal conductivity, Steady-state, Conductive, Thermal modeling, $p / T$ relations to thermal conductivity

\section{Introduction}

In geothermal exploration, temperature models are frequently applied, e.g., for estimating the geothermal potential at depth or for studying the thermal evolution of sedimentary basins (e.g., Balling et al. 2013; Bédard et al. 2018; Békési et al. 2018; Förster et al. 2018; Fuchs et al. 2020; Lemenager et al. 2018; Schintgen et al. 2015a, b; Sonibare et al. 2018; Vélez et al. 2018). The modeled subsurface temperatures are a function of thermal parameters, such as the terrestrial heat flow and mean surface temperature, both

(c) The Author(s) 2020. This article is licensed under a Creative Commons Attribution 4.0 International License, which permits use, sharing, adaptation, distribution and reproduction in any medium or format, as long as you give appropriate credit to the original author(s) and the source, provide a link to the Creative Commons licence, and indicate if changes were made. The images or other third party material in this article are included in the article's Creative Commons licence, unless indicated otherwise in a credit line to the material. If material is not included in the article's Creative Commons licence and your intended use is not permitted by statutory regulation or exceeds the permitted use, you will need to obtain permission directly from the copyright holder. To view a copy of this licence, visit http://creativeco mmons.org/licenses/by/4.0/. 
commonly used as boundary conditions, and the rock-specific thermal properties of the rocks. Under steady-state conductive conditions, one of the most influential parameter is the thermal conductivity $\left(\lambda\right.$, in $\mathrm{W} \mathrm{m}^{-1} \mathrm{~K}^{-1}$ ) of the rock, which in turn, largely depends on $\lambda$ of minerals constituting the rock matrix and on $\lambda$ of the pore fluid (e.g., Blackwell and Steele 1989). Furthermore, $\lambda$ is pressure $(p)$ and temperature $(T)$ dependent (e.g., Schön 1996). Thus, values of $\lambda$ determined under ambient conditions in the laboratory differ from values under higher $p$ and $T$ conditions at greater depths. Therefore, for improving the reliability of thermal models, not only a proper mapping and parameterization of geological (and thermal) units is necessary, but also an understanding of the change of thermal rock properties due to different $p / T$ conditions.

Many laboratory experiments were conducted in which $\lambda$ was measured as a function of either increasing $p$ or $T$. The general trend from the experiments is often referred in textbooks (e.g., Schön 1996, 2011): $\lambda(T)$ is decreasing and $\lambda(p)$ is increasing with increasing $T$ or $p$, respectively. Thus, considering a normal geothermal setting (i.e., where $T$ and $p$ increase with depth), the $p$ and $T$ dependence of thermal properties operate conversely. Usually, $p$ and $T$ dependencies of $\lambda$ are measured separately. Only few data on limited rock types are available, where $\lambda$ was measured simultaneously as a function of $p$ and $T$ (Abdulagatov et al. 2006; Emirov et al. 2017). Perhaps this is one reason why corrections to in situ $\lambda$ are often ignored in thermal modeling (e.g., in the lithosphere thermal models of Noack et al. 2010; Przybycin et al. 2015; Freymark et al. 2017). In other cases, correction to $\lambda$ is claimed being performed, but the correction functions are not provided (e.g., Hasterok and Chapman 2011). Research that only addresses the $T$ dependence of $\lambda$ (e.g., Vosteen et al. 2004; Rühaak et al. 2010; Fuchs and Balling 2016; Lemenager et al. 2018) acknowledges the overriding effect of $T$ over $p$, which results in a decrease of $\lambda$ with increasing depth (Seipold 1995). Studies in which both, $p$ and $T$ correction functions are deployed, were published, for example, by Norden et al. (2008, 2012), Förster et al. (2010, 2018), Schütz et al. (2014), and Schintgen et al. (2015a, b).

There is abundant literature on different functions describing individual $p$ and $T$ correction to $\lambda$. However, only little effort was directed to the quantification of temperature effects that stem from the diversity of these correction functions. This also holds true for quantifying their relevance for geothermal exploration. In addition to ambiguities inherited from the geological setting being modeled (i.e., the structural model and the considered rock types and their initial (ambient) thermal properties), uncertainty in modeled $T$ is strongly controled by the in situ $p$ and $T$ conditions and the in situ $\lambda$. For the central part of the Fennoscandian Shield lithosphere, Kukkonen et al. (1999) discussed variations in calculated temperature and heat-flow density by varying the values of input parameters $\left[\lambda\right.$, heat production $\left(H\right.$, in $\left.\mu \mathrm{W} \mathrm{m}^{-3}\right)$ and lower boundary condition (constant heat-flow density or constant temperature)] as well as the $p / T$-correction parameters for $\lambda$. This study on parameter variations concluded that the $p$ and $T$ effects on calculated $T$ are minor compared to uncertainties resulting from variations in initial $\lambda$ and $H$ or the choice of the lower boundary condition of modeling. Lee and Deming (1998) studied the sensitivity of the various $T$ correction equations to $\lambda$ available for igneous, metamorphic, and sedimentary rocks in the $T$ range $<500{ }^{\circ} \mathrm{C}$. The study resulted in a delineation of absolute and systematic errors in $\lambda$, however, did not proceed towards a quantification of the effects on subsurface temperatures. In conclusion, the effects on subsurface 
temperatures resulting from not applying or only partially applying correction functions remain largely unaccounted for.

The present paper focuses on the thermal impact of $p / T$ corrections at the depth range relevant for the exploration of natural resources and their subsurface utilization (i.e., the uppermost crust). In order to allow an evaluation of different correction schemes for calculating in situ $\lambda$, we only consider steady-state and pure conductive conditions. For a specific setting, transient effects may superimpose the conductive regime, thus significantly affect the thermal regime. Here, we want to concentrate on the general effect of $p / T$ corrections on the thermal field and, therefore, disregard any possible transient processes. In such a conductive regime, temperature prognoses for the depth realm of borehole drillings are fundamental, e.g., for drill site selection and project development. For those projects it is essential to know ambiguities in temperature prediction stemming from ambiguities in calculating in situ $\lambda$. In addressing this issue, we apply available $\lambda$ correction functions in modeling the 2-D temperature distribution along two synthetic geological cross sections. While one section (scenario A) considers a crust entirely composed of igneous and metamorphic rocks, the second section (scenario B) includes sedimentary rocks in the upper part of the profile. These 2-D models quantify $T$ by either (I) not using any $p / T$ correction to $\lambda$, (II) using either a correction of $p$ or $T$, and (III) using combined $p / T$ correction algorithms.

The conditions examined in this paper cover crustal temperatures of $<700{ }^{\circ} \mathrm{C}$. At those $T$, diffusion processes (the lattice or phonon thermal conduction) are typical for polycrystalline rocks exhibiting a decrease in $\lambda$ with increasing $T$ (Schatz and Simmons 1972; Beck 1988; Seipold 1992). This decrease in $\lambda$ is variable, depending on rock type (e.g., Sekiguchi 1984; Zoth and Haenel 1988; Somerton 1992; Seipold 1998; Kukkonen et al. 1999; Vosteen and Schellschmidt 2003; Miranda et al. 2019). The $p$ domain applicable to the crust covers values $<1 \mathrm{GPa}$. In this range, $\lambda$ increases steeply (in an exponential fashion) from ambient conditions towards a pressure of 50-100 MPa (see Hurtig and Brugger 1970; Emirov et al. 2017, and in the compilation by Fuchs and Förster 2014). At higher pressures, $\lambda$ increases gently in a linear fashion. Common linear dependencies are those from, e.g., Horai and Susaki (1989) and Seipold (1992, 1995, 2002). Again, different dependencies are observed for different rock types (e.g., Seipold 1998; Seipold and Huenges 1998; Kukkonen et al. 1999). In our study, we focus on consolidated rocks. Changes of $\lambda$ based on the compaction of sediments during sedimentation are not regarded.

For the reader's convenience, we provide the Additional file 1 to this paper that consists of a compilation of the bulk of the $p$ and $T$ correction functions available in literature, including the conditions under which these relations were derived and the rock type studied. It is apparent that certain functions have limited applicability to the continental crust due to the $p$ and $T$ conditions under which they were constrained. A detailed discussion on the validity of these algorithms, however, is beyond the scope of this paper.

\section{Comparison of correction functions}

Figure 1 shows the variability of common $T$ and $p$ corrections to $\lambda$. The corresponding functions are listed in Additional file 1: Tables S1-S3. The graphs are arranged with respect to the investigated rock type in three main groups: (a) sedimentary rocks and 


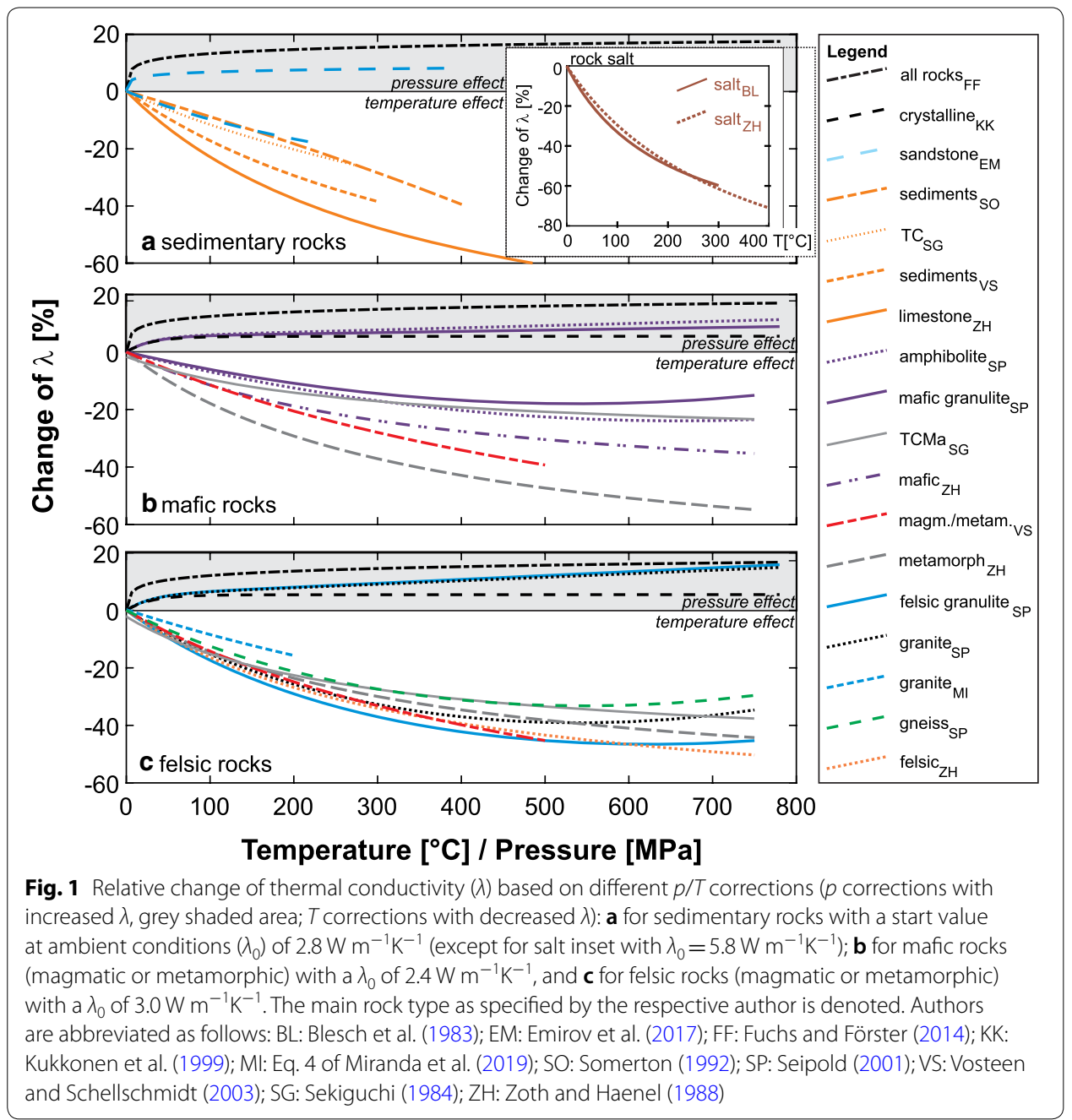

(b) mafic (magmatic or metamorphic) rocks and (c) felsic (magmatic or metamorphic) rocks. All graphs show either the $p$ dependency (greyish area, positive change of $\lambda_{0}$ with increasing pressure) or the $T$ dependency (negative change of $\lambda_{0}$ with increasing temperatures). To account for the different initial $\lambda$ associated with the respective formula, the functions were normalized. So, for each rock type, the shown functions refer to the same ambient laboratory start value $\left(\lambda_{0}\right)$.

Most of the corrections for $T$ follow a non-linear trend for crystalline as well as sedimentary rocks, while the available $p$ corrections demonstrate a linear shape for most of the $p$ range, except for the parameter range 0-50 MPa, in which a non-linear, strong increase of $\lambda$ is observed. The combined $p$-correction equation for sedimentary and magmatic rocks elaborated by Fuchs and Förster (2014; rocks ${ }_{\mathrm{FF}}$ in Fig. 1, see also Additional file 1: Table S2) represents a correction which originates from integrating different published data sets within the parameter range of $p<400 \mathrm{MPa}$ and $\lambda_{0}$-values of $\left.1.5-5 \mathrm{~W} \mathrm{~m}^{-1} \mathrm{~K}^{-1}\right)$. For sedimentary rocks, only the $p$ corrections of Fuchs and Förster (2014) and Emirov et al. (2017, for sandstone only) are available, while available $T$ corrections are numerous. The shape of the curve for sediments after Vosteen and Schellschmidt (2003) generally corresponds with the shape of the curve of Zoth and Haenel 
(1988) derived for limestone, while the correction function supplied by Somerton (1992, cf. also Anand et al. 1973) shows slightly lower correction values running smoothly counter-rotating. The Sekiguchi (1984) correction is based on estimating $T$-corrected $\lambda$ values for the rock matrix. In order to calculate bulk $\lambda$, a constant porosity of $13 \%$ and $T$-dependent fluid thermal properties, as suggested in Deming and Chapman (1988), are applied in Fig. 1a $\left(\mathrm{TC}_{\mathrm{SG}}\right)$. The resulting curve is very close to the one based on the Somerton (1992) correction and shows a trend similar to the $T$ correction of Emirov et al. (2017), who measured one type of sandstone. The study of Emirov et al. (2017) considers the $p / T$ dependency of $\lambda$ in one experimental setup. The authors developed a rock-specific correction function to $\lambda$, involving both $T$ and $p$ (see later in text). In Fig. 1, the graphs of the $p / T$ corrections of Emirov et al. (2017) were calculated for an increase of either $T$ or $p$. Salt rocks display a special thermal behavior: here, a very strong $T$ dependency of $\lambda$ is observed (shown in the inset graph in Fig. 1a). This result is in contradiction to observations of Durham et al. (1980), indicating an insignificant $p$-dependent change of $\lambda$ of salt rocks, at least in the range of 10-50 MPa. The p dependency of $\lambda$ is better constrained for magmatic and metamorphic rocks. Depending on rock type, the correction functions show different slopes (Fig. 1b, c). All p-correction functions are within a range defined by two generalized functions: the Fuchs and Förster (2014) function for sedimentary plus magmatic rocks at the upper end and the correction function given by Kukkonen et al. (1999) for crystalline crustal rocks at the lower end. For this type of rock, Kukkonen et al. (1999) determined a mean value for the linear $p$ increase. In Fig. 1, their relation was extended to account for the non-linear $\lambda$-pressure relation established by Seipold (2001). The $T$-related change of $\lambda$ is more diverse for mafic rocks relative to felsic rocks. While most functions for felsic rock types follow more or less the same trend, the application of the function provided by Miranda et al. (2019) results in a notably smaller reduction of $\lambda$ compared to any other correction function. These authors measured the thermal properties of a granite exhibiting a moderate heat production of about $5 \mu \mathrm{W} \mathrm{m}{ }^{-3}$.

The herein conducted analytical study of the different correction functions permits the delineation of a possible minimum and a maximum correction applied to $\lambda$ (Table 1). Combining the $p$-correction equation showing the minimum effect on $\lambda_{0}$ with the $T$-correction equation showing the maximum effect on $\lambda_{0}$ and vice versa enclose a combined maximum and minimum effect on $\lambda_{0}$, respectively. However, it is still an open question whether calculating the in situ thermal properties by considering the effects of $p$ and Ton $\lambda$ individually is a valid approach.

Table 1 Applied corrections to estimate the potential impact of $p / T$-related corrections of thermal conductivity $(\lambda)$

\begin{tabular}{|c|c|c|}
\hline \multirow[t]{2}{*}{ Rock type } & \multicolumn{2}{|c|}{ Minimum/maximum change of $\lambda_{0}$ based on } \\
\hline & $\begin{array}{l}p \text { correction } \\
(\uparrow \lambda \text { with pressure) }\end{array}$ & $\begin{array}{l}T \text { correction } \\
(\downarrow \lambda \text { with temperature) }\end{array}$ \\
\hline Sedimentary & No correction/rocks ${ }_{\mathrm{FF}}$ & Sediments $_{\text {so }}$ sediments $_{V S}$ \\
\hline Mafic rocks (magmatic/metamorphic) & Crystalline $_{\mathrm{kk}} /$ rocks $_{\mathrm{FF}}$ & Mafic granulite $_{\mathrm{SP}} /$ metamorphic $_{\mathrm{ZH}}$ \\
\hline Felsic rocks (magmatic/metamorphic) & Crystalline $_{\mathrm{kk}} /$ rocks $_{\mathrm{FF}}$ & Granite $_{\mathrm{mi}} /$ felsic granulite $_{\mathrm{SP}}$ \\
\hline
\end{tabular}

For abbreviations see Fig. 1 
In this study, we calculated $\lambda_{\text {in situ }}$ by three methods: firstly, by applying the $T$ correction before undertaking the $p$ correction of $\lambda[\lambda(T, p)]$, secondly, by applying the $p$ correction before performing the $T$ correction of $\lambda[\lambda(p, T)]$, and thirdly, by applying a combined correction function of the individual corrections $[\lambda(p+T)]$ calculated as $\lambda_{\text {in }}$ situ $=\lambda_{0}-\left[\left(\lambda_{0}-\lambda(p)\right)+\left(\lambda_{0}-\lambda(T)\right)\right]$. As long as the respective $p / T$-correction equation used represents an additive $\lambda_{0}$ system (i.e., $\lambda_{0}$ will not be included as a factor), the third approach will yield the same result as the two other approaches. In this study, most of the considered $p$-correction equations are respecting $\lambda_{0}$ in a factorized term, while the majority of the $T$-correction equations do not. For these cases, method three will yield the same results as method two, but differ from those resulting from method one. Furthermore, the $T$-correction correction formulae for sedimentary rocks of Vosteen and Schellschmidt (2003) and Somerton (1992) are also incorporating $\lambda_{0}$ as a factor. Thus, for their $T$-correction functions, the third method will show results different from the other two methods. To illustrate the different correction approaches, the following scenario is considered: $\lambda_{0}$ determined under ambient conditions amount to $2.8 \mathrm{~W} \mathrm{~m}{ }^{-1} \mathrm{~K}^{-1}$ and the expected in situ $p / T$ conditions is represented by $p=120 \mathrm{MPa}$ and $T=130{ }^{\circ} \mathrm{C}$, respectively. For the correction of $\lambda_{0}$ to in situ conditions, the equations rocks $\mathrm{FF}_{\mathrm{FF}}$ ( $p$ correction) and sediments ${ }_{\mathrm{SO}}$ ( $T$ correction) will be taken into account, respectively (e.g., Fig. 1, Table 1, Additional file 1). The first method $[\lambda(T, p)]$ will result in a $\lambda_{\text {in situ }}$ of 2.649 $\mathrm{W} \mathrm{m} \mathrm{m}^{-1} \mathrm{~K}^{-1}$, the second method $[\lambda(p, T)]$ will yield a $\lambda_{\text {in situ }}$ of $2.654 \mathrm{~W} \mathrm{~m}^{-1} \mathrm{~K}^{-1}$, and $\lambda_{\text {in situ }}$ calculated by the third method $[\lambda(p+T)]$ will yield a value of $2.767 \mathrm{~W} \mathrm{~m}^{-1} \mathrm{~K}^{-1}$.

Emirov et al. (2017) presented a formulation of the dependency of $\lambda$ on $p$ and $T$ for one type of sandstone. They observed that $p$ has also a direct influence on the $T$ dependency of $\lambda$, implying that a simple arithmetic approach for combining single $p / T$ corrections may represent an unpermitted oversimplification.

To illustrate the impact of the implementation of different correction equations on the temperature field, we studied two synthetic geological models, which will be presented in the next section.

\section{Conceptual crustal models and their parameterization}

The 2-D thermal models studied in this paper reflect different geological conditions in the uppermost $7 \mathrm{~km}$ of the Earth's crust (Fig. 2). Scenario A covers different types of magmatic and metamorphic rocks. It is inspired by geological models developed for the western Erzgebirge and the adjacent Elbe Zone in the central European Saxothuringian chain of the Variscan orogeny in Germany (Förster et al. 2018), characterized by the emplacement of voluminous igneous rocks in the upper crust. In contrast, scenario B accounts for a sedimentary setting with more or less horizontal layering, only locally deformed by salt tectonics. This scenario encompasses different types of sedimentary rocks and two prominent salt structures (a salt pillow and a salt diapir). This scenario resembles a setting typical for European Permian sedimentary basins in general, and for the North German Basin in particular.

The two conceptual geological 2-D models are subdivided into units/polygons of contrasting thermal properties ( $\lambda$ and $H$ ) (Table 2, scenarios A and B). In the depth range $7-30 \mathrm{~km}$, both upper crustal geological models have the same type of layered crust (Table 2, basement). The structure and composition of these basement units are 

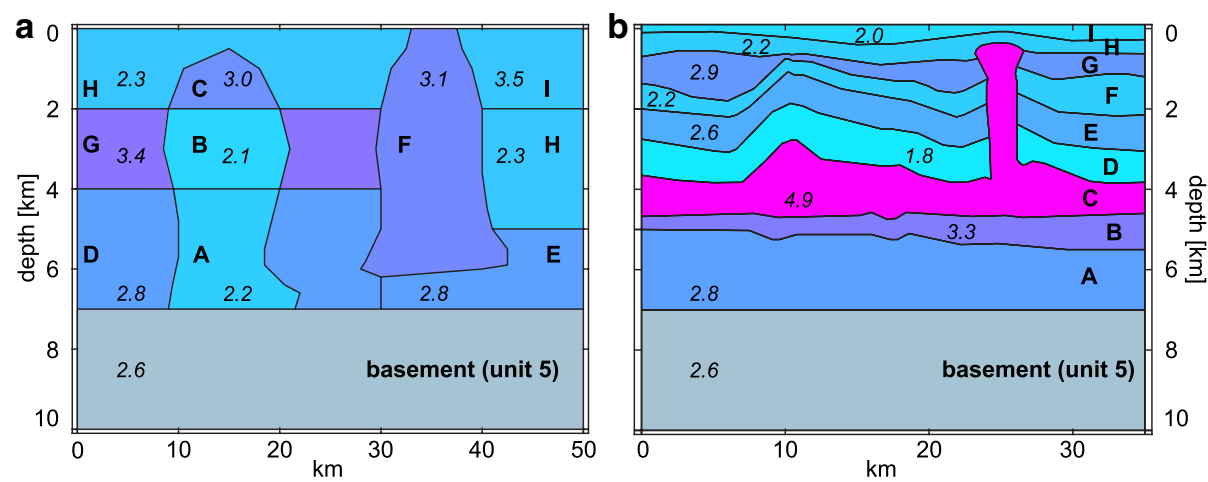

Fig. 2 Conceptual 2-D models (uppermost $10 \mathrm{~km}$ ) a of a magmatic and metamorphic crust (vertical exaggeration approx. fourfold) and $\mathbf{b}$ of a sedimentary crust (vertical exaggeration approx. threefold). The model rock units (bold capital letters) and the corresponding thermal conductivity under ambient conditions (in italics, given in $\mathrm{W} \mathrm{m}^{-1} \mathrm{~K}^{-1}$ ) are denoted (see Table 2)

equivalent to those reported for the Erzgebirge in Germany (Förster and Förster 2000), to account for realistic crustal scenarios. The thermal properties and density values assigned to rock types represent typical ambient textbook values. To investigate the effect of $p / T$ corrections on the temperature field, different simulations are performed with: (1) no $p / T$ correction; (2) only a $p$ correction of $\lambda_{0}$, to account for the maximum $p$ contribution $[\lambda(\max p)]$; (3) only a $T$ correction of $\lambda_{0}$, to account for the maximum $T$ contribution $[\lambda(\max \boldsymbol{T})]$, and (4) combined $p / T$ corrections as discussed previously (see "Comparison of correction functions" section). The correction formulas were selected according to the possible minimum as well as maximum corrections to $\lambda_{0}$ with respect to the main rock type (Table 1, Fig. 1). For scenario B (sedimentary crust), we additionally compare the effect of applying or disregarding the correction formula for the $T$ dependency of the $\lambda$ of rock salt as well as its possibly $p$-independent thermal behavior.

\section{Thermal modeling}

\section{Numerical procedure}

For 2-D modeling, the equation for the steady-state heat conduction is given by

$$
\frac{\partial}{\partial x}\left(\lambda \frac{\partial T}{\partial x}\right)+\frac{\partial}{\partial z}\left(\lambda \frac{\partial T}{\partial z}\right)=-H
$$

where $H$ represents the internal heat production and $\lambda$ is assumed to be isotropic. The equation was solved numerically. The temperature distribution $T(x, z)$ within the lithosphere (with $(x)$ the horizontal coordinate and $(z)$ the vertical coordinate) is determined by the temperature-dependent and pressure-dependent thermal conductivity distribution $\lambda(x, z)$, the heat production distribution $H(x, z)$, and the appropriate thermal boundary conditions. The heat equation is solved by the finite-element approach using the PDE toolbox of the software MATLAB R2018a. The finite-element mesh size is variable according to the different size of the crustal polygons. Thin polygons representing the sedimentary formations or polygons close to the surface have a mesh size of less than $200 \times 200 \mathrm{~m}$, and those of larger size, representing the deeper crust, show a mesh size of up to $1 \times 1 \mathrm{~km}$. 


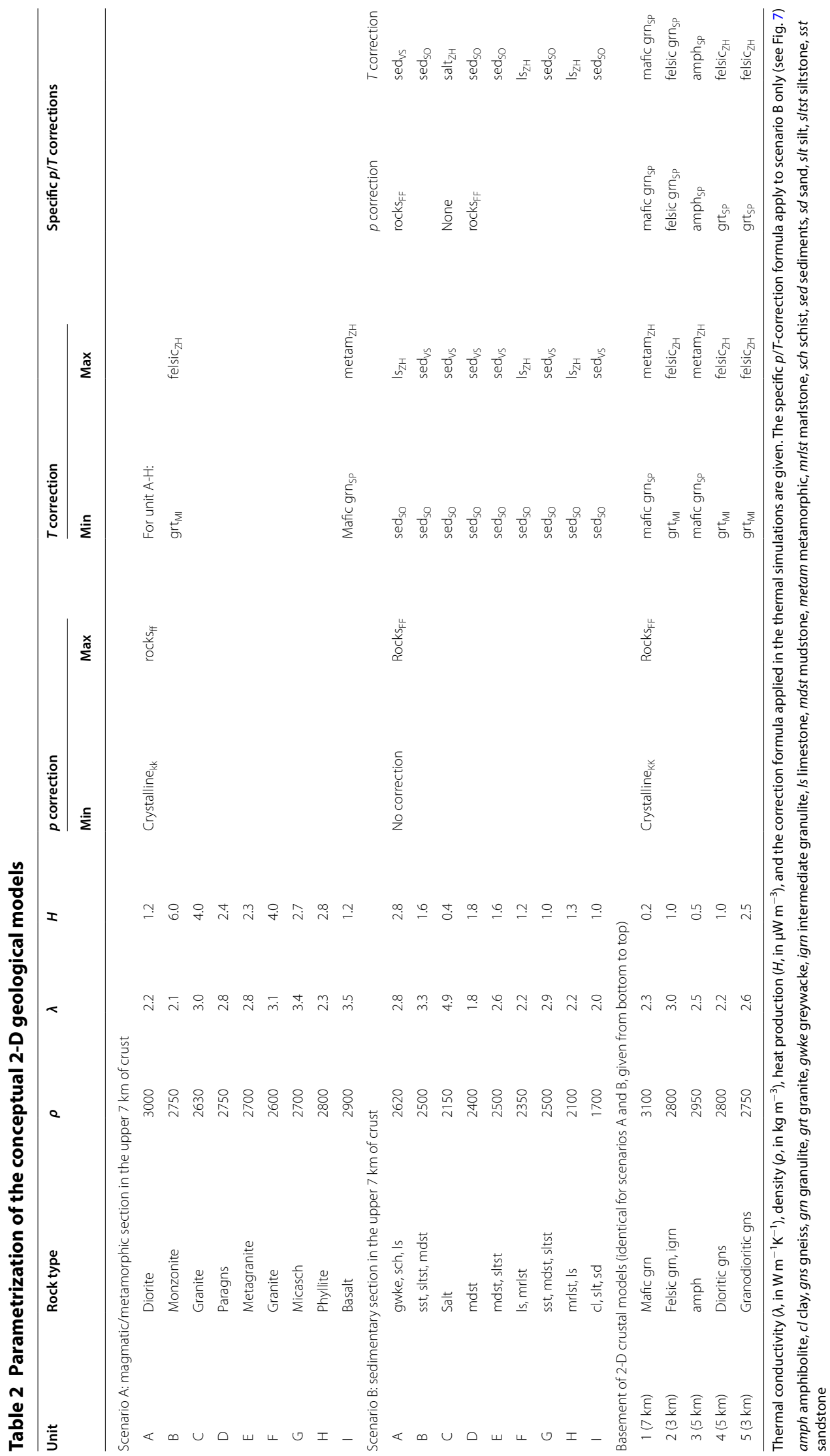




\section{Boundary conditions}

In the 2-D thermal models, a constant surface temperature of $10^{\circ} \mathrm{C}$ is assumed. In addition to the upper temperature boundary, the models involve a lower boundary constraint, representing a constant heat-flow boundary. A value of $30 \mathrm{~mW} \mathrm{~m} \mathrm{~m}^{-2}$ at a depth of $30 \mathrm{~km}$ represents the initial baseline for both scenarios (magmatic and sedimentary). At the site boundaries of the 2-D models, horizontal temperature gradients are assumed to be zero (no horizontal heat transfer). To exclude any significant influence of the site boundary conditions on the modeling results along the main sections, the models were extended by $50 \mathrm{~km}$ on each site, respectively.

\section{Results}

Figure 3 shows the effect of applying the maximum $p$ correction $(\lambda(\max \boldsymbol{p})$, considering no $T$ correction) and the maximum $T$ correction $(\lambda(\max T)$, considering no $p$ correction) on ambient $\lambda$ values (see Table 2). For comparison, the $T$ calculated with no $p / T$ correction on $\lambda$ is given. Obviously, the $T$ differences between the different approaches increase strongly with depth. Based on the respective $p$ and $T$ correction applied, the possible in situ $T$ values may deviate from the non-corrected $T$ profile. The maximum difference between $\lambda(\max \boldsymbol{p})$ and $\lambda(\max \boldsymbol{T})$ could be used as an indicator for the uncertainty of $T$ prognosis using correction functions. It accounts for about $8{ }^{\circ} \mathrm{C}$ at $2 \mathrm{~km}$ depth and to about $55{ }^{\circ} \mathrm{C}$ at $8 \mathrm{~km}$ depth, respectively. At the same time, the $T$ dependency of $\lambda$ is, compared to the $p$ dependency of $\lambda$, more pronounced. Although the model scenarios contain different rock types exhibiting different thermophysical parameters, these general observations are the same. However, the rock parameterization gives rise to thermal anomalies in both scenarios. For section A, the radioactive (hot) magmatic monzonite (unit B, Table 2) in the depth interval 2-4 km (Fig. 1) causes a positive thermal anomaly below $3.5 \mathrm{~km}$ depth, while the higher $\lambda$ value of the granitic unit above the monzonite body (unit $\mathrm{C}$ ) is responsible for a decrease in $T$ in that area (see $T$ profile at $2 \mathrm{~km}$ depth, Fig. 3). The high $\lambda$ value of the basaltic rock complex in the eastern part of section $\mathrm{A}$ (unit I) causes the comparably low $T$ values in that section to a depth of about $5 \mathrm{~km}$. For section B, the most prominent feature in the $T$ pattern is due to the salt structures, providing great contrasts in $\lambda$ values. Due to the chimney effect of the higher conductive salt, $T$ is increased at the salt diapir by about $5{ }^{\circ} \mathrm{C}$ close to the surface (section $\mathrm{B}, 0.5 \mathrm{~km}$ ). The same chimney effect at the salt diapir is responsible for lower $T$ values (compared to surrounded profile $\mathrm{km}$ ) at depths of $2.0-8.0 \mathrm{~km}$, with a maximum deviation at about $3.5 \mathrm{~km}$ depth. If instead of the correction function sediments $\mathrm{VS}_{\mathrm{VS}}$, the correction formula salt $_{\mathrm{ZH}}$ is applied for the salt unit, the chimney effect would slightly increase, however, not changing the overall pattern of the $T$ field. Whereas the maximum $T$ and $p$ corrections account for the maximum possible influence on the simulated thermal field (Fig. 3), the possible influence of a combined correction is shown in Fig. 4.

Due to the differences in thermal properties of the modeled rock units in scenario A, the resulting $T$ distribution for a certain depth level shows a much larger range relative to sedimentary scenario B (Fig. 4). In the calculation, a minimum $p / T$ correction (based on the presented single corrections for $p$ and $T$ ) and a maximum $p / T$ correction was considered. Based on the selected correction functions for scenario 

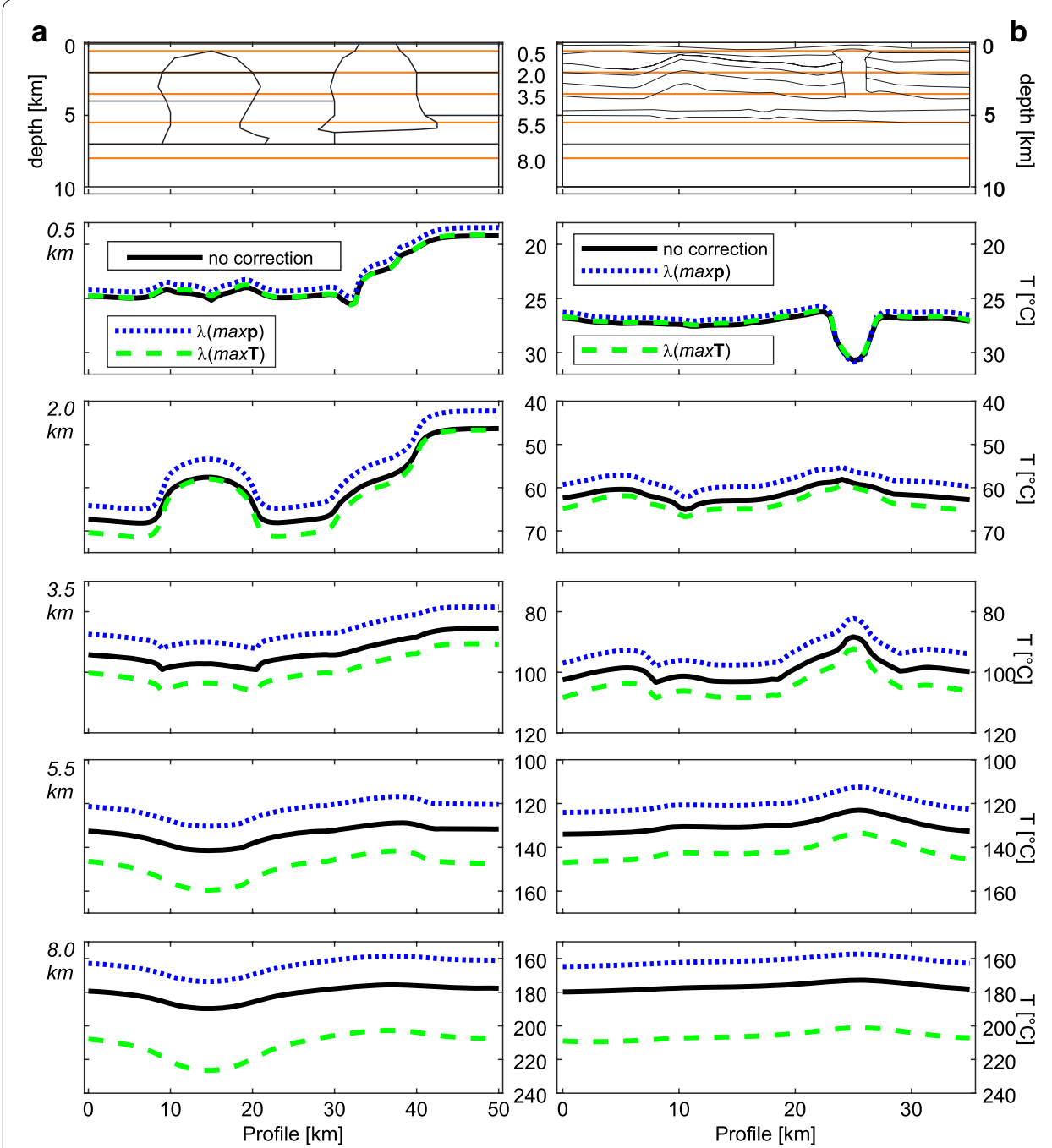

Fig. 3 Temperature profiles for different depth levels. a For the magmatic-metamorphic scenario and $\mathbf{b}$ for the sedimentary scenario considering the respective thermal effect (i) of a maximum pressure ( $p$ ) correction $[\lambda(\max \boldsymbol{p})]$ of the ambient thermal conductivity; (ii) of a maximum temperature $(T)$ correction $[\lambda(\max \boldsymbol{T})]$ of the ambient thermal conductivity, and (iii) of no correction of the ambient thermal conductivity on the respective thermal field. For data input see Table 2

A (Table 2), different ways of combination of $p / T$ corrections are applied on $\lambda: \lambda(p, T)$ with the minimum case $\lambda(\max \boldsymbol{p}, \min \boldsymbol{T})$ and the maximum case $\lambda(\min \boldsymbol{p}, \max \boldsymbol{T}), \lambda(T, p)$ with the minimum case $\lambda(\min \boldsymbol{T}, \max \boldsymbol{p})$ and the maximum case $\lambda(\max \boldsymbol{T}, \min \boldsymbol{p})$, and $\lambda(p+T)$ for the minimum case. For the maximum case, $\lambda(p+T)$ will show the same results as $\lambda(p, T)$ because the applied $T$ correction is following an additive manner. In $10 \mathrm{~km}$ depth, the uncertainty amounts to about $30{ }^{\circ} \mathrm{C}$ and increases towards greater depths (not shown in Fig. 4). For scenario B, the same type of combinations of $p / T$ corrections was considered. However, in scenario $\mathrm{B}$, the maximum case (maximum $T$ and minimum $p$ ) refers to no $\mathrm{p}$ correction (Table 2, scenario $\mathrm{B}$ ), therefore (although the applied $T$ correction is not additive), $\lambda(\min \boldsymbol{p}+\max \boldsymbol{T})$ equals $\lambda(\min \boldsymbol{p}, \max \boldsymbol{T})$ (not shown in Fig. $4 \mathrm{~b})$. For both scenarios, calculating $T$ based on $\lambda(\max p+\min T)$ yields 

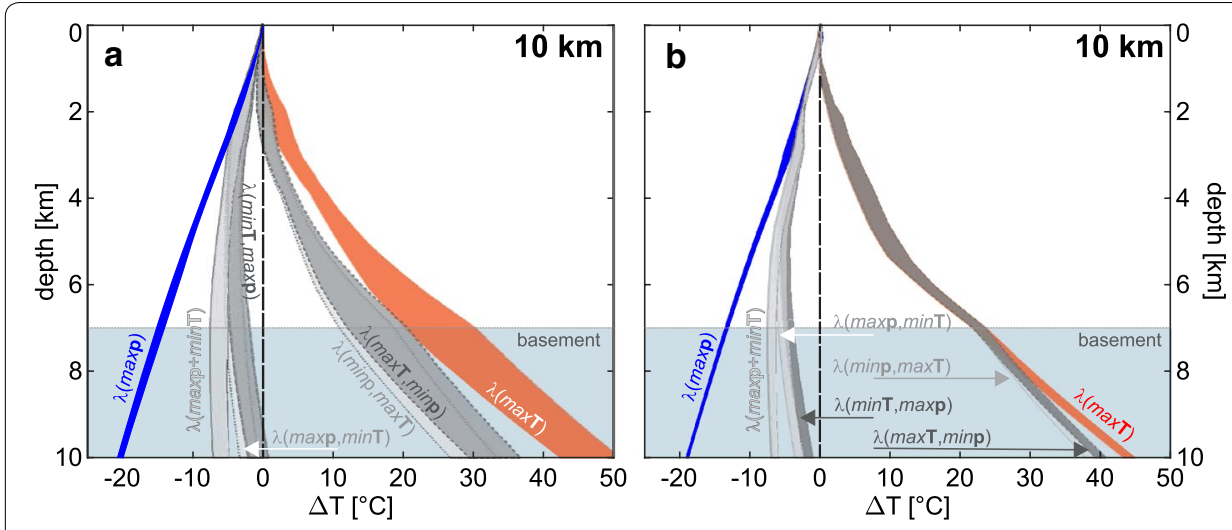

Fig. 4 Temperature difference $(\Delta T)$ plots showing the impact of the different thermal conductivity $(\lambda)$ correction equations on the modeled temperature field for the uppermost $10 \mathrm{~km}$ of the upper crust. The bandwidth of the curves show the range of the obtained $\Delta T$ in the respective depth level. Several cases for studying the minimum and maximum impact of applying correction functions are considered: only pressure correction of $\lambda[\lambda(\max \boldsymbol{p})]$, only temperature correction of $\lambda[\lambda(\max \boldsymbol{T})]$, and the main rock type-specific combined minimum and maximum $p / T$ corrections according to Tables 1 and 2. a Magmatic-metamorphic scenario with two ways of $p / T$ corrections for minimum $[\lambda(\max \boldsymbol{p}, \min \boldsymbol{T})$ and $\lambda(\min \boldsymbol{T}, \max \boldsymbol{p})]$ and maximum $[\lambda(\min \boldsymbol{p}, \max \boldsymbol{T})$ and $\lambda(\max \boldsymbol{T}, \min \boldsymbol{p})]$ of $\Delta T$, respectively. $\mathbf{b}$ Sedimentary scenario with 3 ways of $p / T$ corrections for the minimum case $[\lambda(\max \boldsymbol{p}+\min \boldsymbol{T}), \lambda(\max \boldsymbol{p}, \min \boldsymbol{T})$ and $\lambda(\min \boldsymbol{T}, \max \boldsymbol{p})]$ and two ways of $p / T$ corrections for the maximum case $[\lambda(\min \boldsymbol{p}, \max \boldsymbol{T})$ and $\lambda(\max \boldsymbol{T}, \min \boldsymbol{p})]$

slightly larger $T$ differences than based on $\lambda(\max p, \min T)$. In comparison, the bandwidth of the $T$ range for a given depth and correction mode is less pronounced for the sedimentary scenario than for the magmatic-metamorphic cross section (scenario A). This is related to the geometry and the parameterization of scenario A, which is less structurally manifold than scenario B and introduces also lateral heat flow, resulting in a greater $T$ variation. Depending on the configuration of the correction approach, $T$ may differ by about $40{ }^{\circ} \mathrm{C}$ in $8-10 \mathrm{~km}$ depth.

To shed more light on the possible effects on the $T$ field as function of the geological setting and the linked thermal properties, Figs. 5 and 6 show a selection of $T$ and $\Delta T$ profiles of certain positions along the 2-D section for the igneous and the sedimentary scenario, respectively. The uncorrected $T$ profiles (upper part of Figs. 5 and 6) depend on the respective model parameterization and the basal heat flow condition. Thus, the $T$ gradient changes with respect to $\lambda$ of the involved model polygons. For the igneous scenario, the possible effect of $p / T$ corrections is given by the $T$ difference originating from the different correction modes and for an increased and a reduced basal heat flow. Corrections considering the $p$ dependency of $\lambda$ may result in a reduction of about $20^{\circ} \mathrm{C}$ compared to uncorrected parameters at $10 \mathrm{~km}$ depth, while considering only the $T$ dependency may end up with $T$ estimates increased by more than $40{ }^{\circ} \mathrm{C}$ compared to $T$ based on uncorrected $\lambda$ and a basal heat flow of $30 \mathrm{~mW} \mathrm{~m}{ }^{-2}$ (at $30 \mathrm{~km}$ depth). Bordered by the two lines of maximum $p$ and $T$ corrections (given by $\lambda(\max \boldsymbol{p})$ and $\lambda(\max \boldsymbol{T})$ in Fig. 5$)$ is the branch of possible in situ $T$ conditions. Applying the maximum effect of a combined correction (by correcting firstly for $p$ and subsequently for $T$ or vice versa) has a strong impact on the modeling result. Remarkably, the effect of a $\lambda(\max \boldsymbol{T})$ or a $\lambda(T, p)$ correction on the temperature is on the same order of magnitude as an increase (or decrease) of the basal heat flow in the order of $25 \%$ 


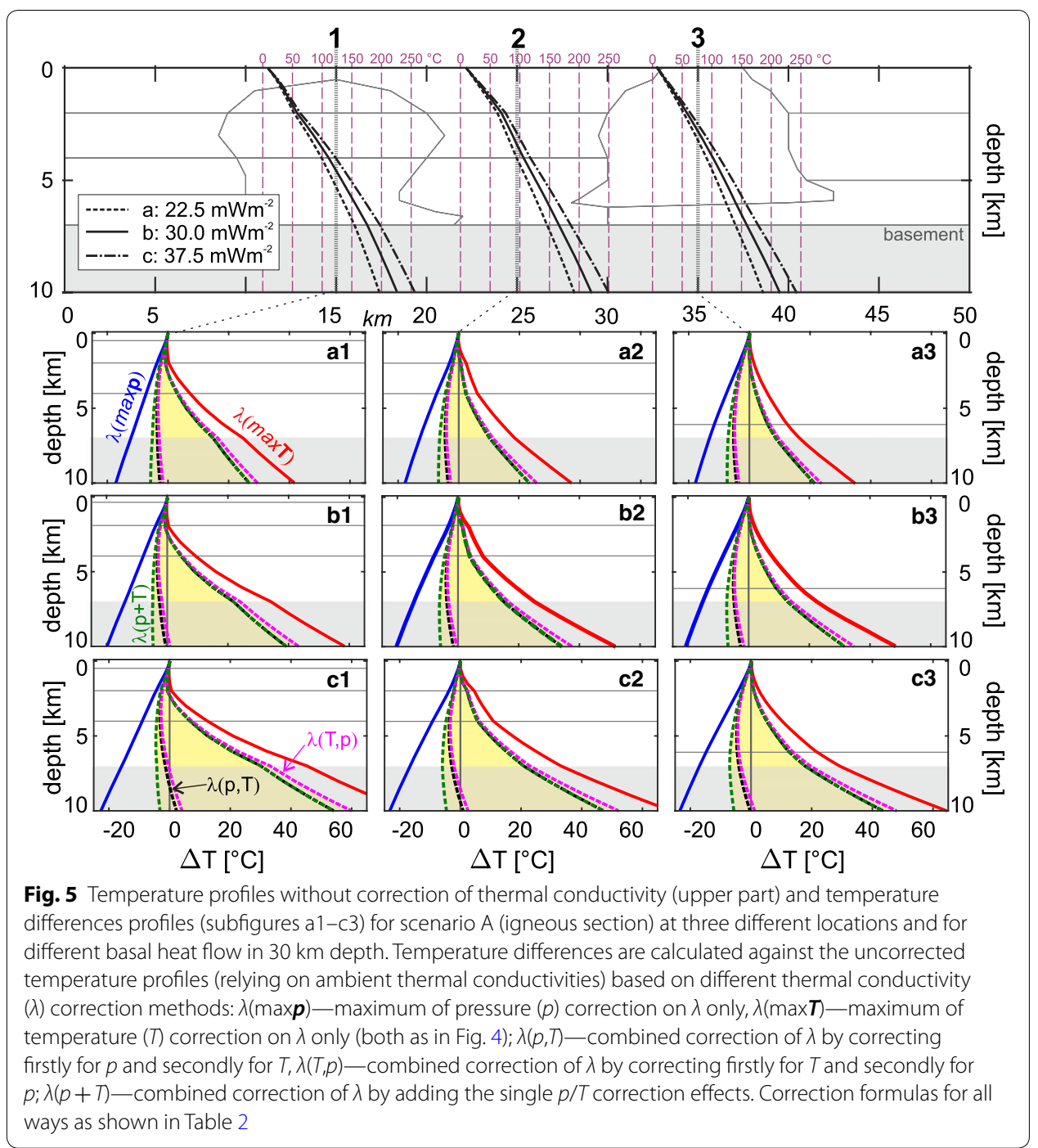

while not applying a correction method of $\lambda$ (resulting in a $\Delta T$ of about $28^{\circ} \mathrm{C}$ at $10 \mathrm{~km}$ depth, see upper panel of Figs. 5 and 6). If $T$ corrections of $\lambda$ are applied, a 25\% reduction in basal heat flow $\left(22.5 \mathrm{~mW} \mathrm{~m}^{-2}\right)$ results in a less pronounced effect on $T$, while a $25 \%$ increase in heat flow $\left(37.5 \mathrm{~mW} \mathrm{~m}^{-2}\right)$ produces a much greater uncertainty of the calculated $T$.

Figure 6 shows the situation for the sedimentary scenario. If we compare the influence of an increased or reduced basal heat flow on the calculated $T$ correction of $\lambda$ and the thermal field, the situation is similar to the igneous case: the higher $T$ of an increased heat flow is responsible for an enhanced $T$ correction of $\lambda$ and, thus, a higher $\Delta T$ (Fig. 6, upper and lower panels). In contrast to the general-rock-type correction applied for the igneous scenario (Fig. 5, Table 1), a lithotype-specific scenario (accounting for reasonable rock-specific corrections, see Table 2) is presented in Fig. 6 , in addition to applying the extreme corrections $[\lambda(\max p)$ and $\lambda(\max T)]$. While the maximum effect of an applied p correction or $T$ correction is similar to the igneous scenario, resulting in a $\Delta T$ of $-20{ }^{\circ} \mathrm{C}(\lambda(p))$ or $+40{ }^{\circ} \mathrm{C}(\lambda(T))$ at $10 \mathrm{~km}$ depth 


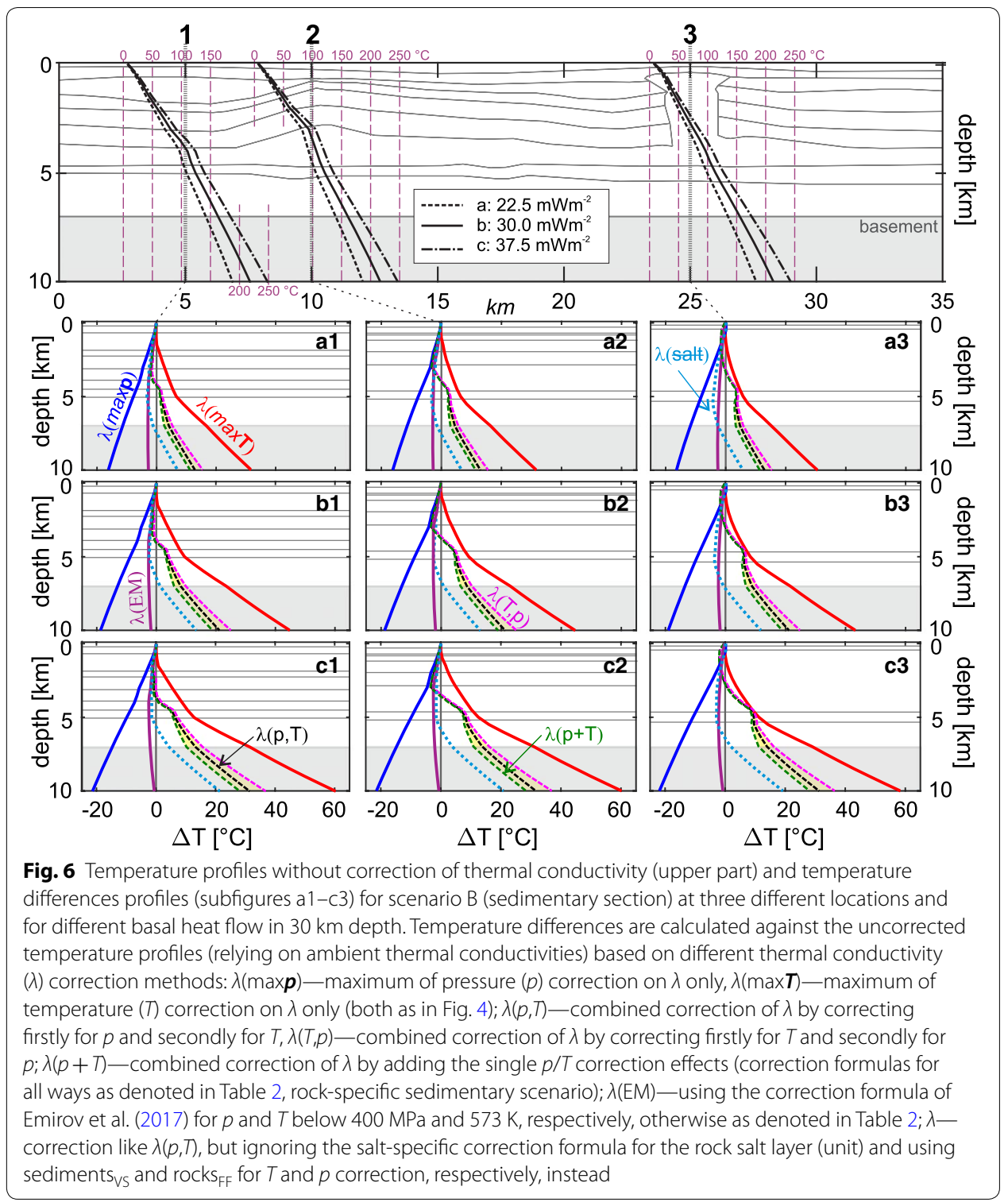

(with a heat flow of $30 \mathrm{~mW} \mathrm{~m}{ }^{-2}$ ), the graphs of a combined $p / T$ correction of the lithotype-specific scenario show a much narrower min/max range of about $20{ }^{\circ} \mathrm{C}$ (for $\lambda(p, T))$ to $25^{\circ} \mathrm{C}$ (for $\left.\lambda(T, p)\right)$.

A distinctive feature of the sedimentary setting in scenario $B$ is the presence of rock salt, which shows a $\lambda$ higher than most common sedimentary rocks. The rock-specific combined $p / T$ corrections $(\lambda(p, T)$ and $\lambda(T, p)$ in Fig. 6) do honor the salt-specific $p / T$ dependency formulations (Table 2). They result in a stronger reduction of the ambient $\lambda$ and do not correct for $p$ effects, thus lead to comparable higher $T$ values, very close to the maximum $T$ correction $[\lambda(T)]$ in the salt diapir (a3, b3, c3 in Fig. 6). If, however, a non-salt specific correction formula is applied (e.g., using sediments $\mathrm{VS}_{\mathrm{VS}}$ and rocks $\mathrm{FF}_{\mathrm{FF}}$ for $T$ and $p$ correction, respectively), the $T$ is very close to the $T$ profile based on the uncorrected ambient $\lambda$ values for the uppermost $7 \mathrm{~km}(\lambda$, Fig. 6$)$. 
We additionally applied the Emirov et al. (2017) $p / T$ correction approach to the sedimentary scenario $B$, assuming that all sedimentary rocks show a similar thermal characteristic as the sandstone investigated in their study ( $\lambda(\mathrm{EM})$, Fig. 6). The resulting $T$ profile (or $\Delta T$ in Fig. 6) of the $\lambda(\mathrm{EM})$ correction shows a remarkable $T$ contour: it follows more or less the reference $T$ profile (based on ambient and uncorrected $\lambda$ values), indicating also slightly lower values for the uppermost $10 \mathrm{~km}$ of the crust. Moreover, it is more or less in line with the no-salt scenario $[\lambda]$ for the uppermost $5 \mathrm{~km}$ indicating that it may be a valid approach for siliciclastic rock types. However, at greater depths, $\lambda(\mathrm{EM})$ deviates significantly from the other correction modes.

\section{Discussion}

The impact of $p / T$ corrections applied to ambient $\lambda$ values of rocks implemented in thermal field modeling is manifold and depends on the structural-geological setting and the basal heat flow. For the model scenarios treated in this study, the correction equations account for uncertainties in the $T$ simulation on the order of $50-80{ }^{\circ} \mathrm{C}$ at $10 \mathrm{~km}$ depth, also depending on the basal heat flow (see Figs. 5 and 6, lower panels). With increasing depth, the $p$ effect has generally a minor impact on $\lambda$ compared to the $T$ effect. Therefore, the $\mathrm{p}$ effect remains mostly unaccounted for in thermal modeling (e.g., Lemenager et al. 2018; Miranda et al. 2019). However, disregarding the p correction may give rise to an overestimation of $T$ on the order of $20-30{ }^{\circ} \mathrm{C}$ at $7-10 \mathrm{~km}$ depth. Although one could argue that such a difference is within the uncertainty of the thermal parametrization of subsurface models, the error reflects a methodological weakness that needs to be addressed in more detail. Our modeling of the synthetic scenarios shows that it is not trivial to account for the in situ $\lambda$ correction by considering correction functions almost exclusively developed for either a $p$ correction or a $T$ correction to $\lambda$. As expected, the correction sequence (first $p$ correction and then $T$ correction, or vice versa) has a direct influence on in situ $\lambda$ and the calculated T. Normally, $\lambda$ is corrected first for $p$ and second for $T$ (cf. Kukkonen et al. 1999). From a general point of view, this might be a sound option: $p$ is always increasing with depth and shows normally a much lower order of variability for a certain depth level as $T$; $T$ may vary strongly with depth due to other heat sources or sinks, such as magmatic intrusions, cooling fluids, etc. De facto, the choice is speculative. In consequence, applying first the $p$ correction and subsequently the $T$ correction will end up with lower $T$ values than the other way round. The reason is that by applying the $T$ correction first, the ambient $\lambda$ (especially at greater depths and for higher ambient $\lambda$ values) will be lowered much larger than by the increase of $\lambda$ in response to the applied $p$ correction (see Fig. 1). Thus, the starting value of $\lambda$ for the $p$ correction will be significantly lower. This discussion clearly underlines the need of specifically designed experiments, in which the dependence of $\lambda$ on $p$ and $T$ could be measured simultaneously. The research of Emirov et al. (2017) fills this gap, presenting an attempt for the development of an integrated $p / T$ correction formula. However, their equation relies on too few measurements performed under in situ conditions and is limited to one single rock type (sandstone). Furthermore, the derivation of their equation is not completely transparent, so that supposing a more comprehensive (i.e., independent on rock type) application of the Emirov et al. (2017) equations as exemplarily done in this study (Fig. 6) is not feasible. However, the study of Emirov et al. (2017) may indicate that an individual 
correction of $\lambda$ for the respective $p$ and $T$ condition (such as $\lambda(p, T)$ and $\lambda(T, p)$ in Figs. 5 and 6) most likely does not meet the real in situ conditions. To sharpen the thermal modeling, more $\lambda$ measurements considering in situ conditions (accounting for $p$ and $T$ simultaneously) are required to better understand the rock-specific thermal behavior. Until more correction experiments have been conducted, any calculation of the thermal field has to struggle with the discussed ambiguities. In order to get a first approximation of the uncertainty relating to the technical modeling procedure, any of the $T$ models applying (single) $p / T$ corrections to $\lambda$ should specify in detail, which corrections were applied, and in which sequence.

In connection with the synthetic models the question arises, whether the applied $p / T$ corrections also influence the modeled surface heat flow. In fact, applying or not applying $p / T$ corrections has a minor effect (Fig. 7). Only if strong $\lambda$ contrasts due to the correction equations are achieved, the surface heat flow is significantly affected. This is the case for salt structures in sedimentary environments. In nearly all other cases, the surface $(T-)$ boundary condition and the similar pressures at shallow depths do not cause any significant change of the surface heat flow. Notably, the thermal properties of the rock types cause a gentle re-distribution of the radiogenic heat. High surface heat-flow values of the magmatic section (Fig. 7a) do correlate with heat refraction processes at rock contacts, while high surface heat-flow values in the sedimentary section are triggered by the chimney effect of the high-conductive rock salt (Fig. 7b).

However, applying or not applying $p / T$ corrections will notably alter the calculated subsurface heat flow. This has consequences for the calculation of heat flow, which generally takes advantage of drillings (drill cores and rock samples) and well-log data (temperature logs). One common way of heat-flow determination is the interval method (e.g., Powell et al. 1988), which involves the calculation of the product of the $T$ gradient and the $\lambda$ for a certain depth interval according to Fourier's law. If $\lambda$ is measured on rock samples under ambient conditions, the in situ $\lambda$ needs to be calculated. Depending on the applied correction functions, the determined heat flow may vary considerably (Fig. 8). In

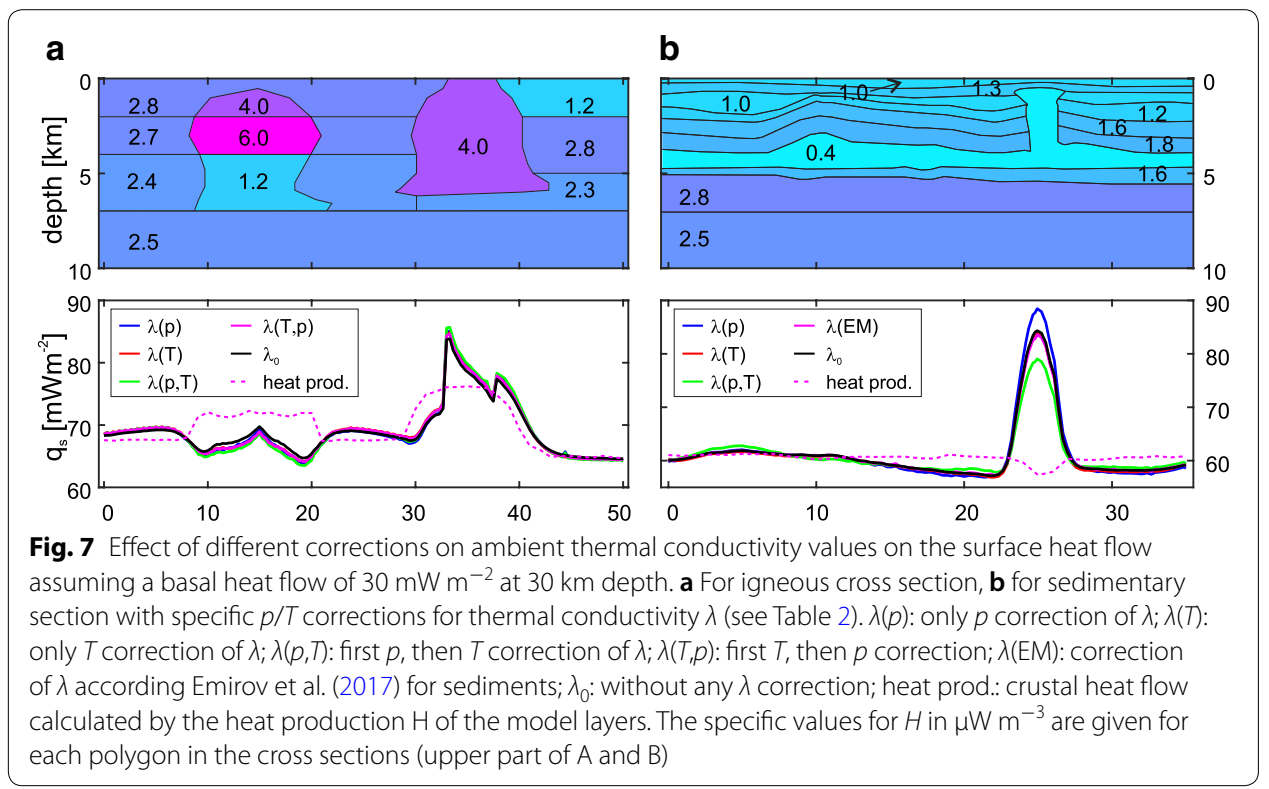




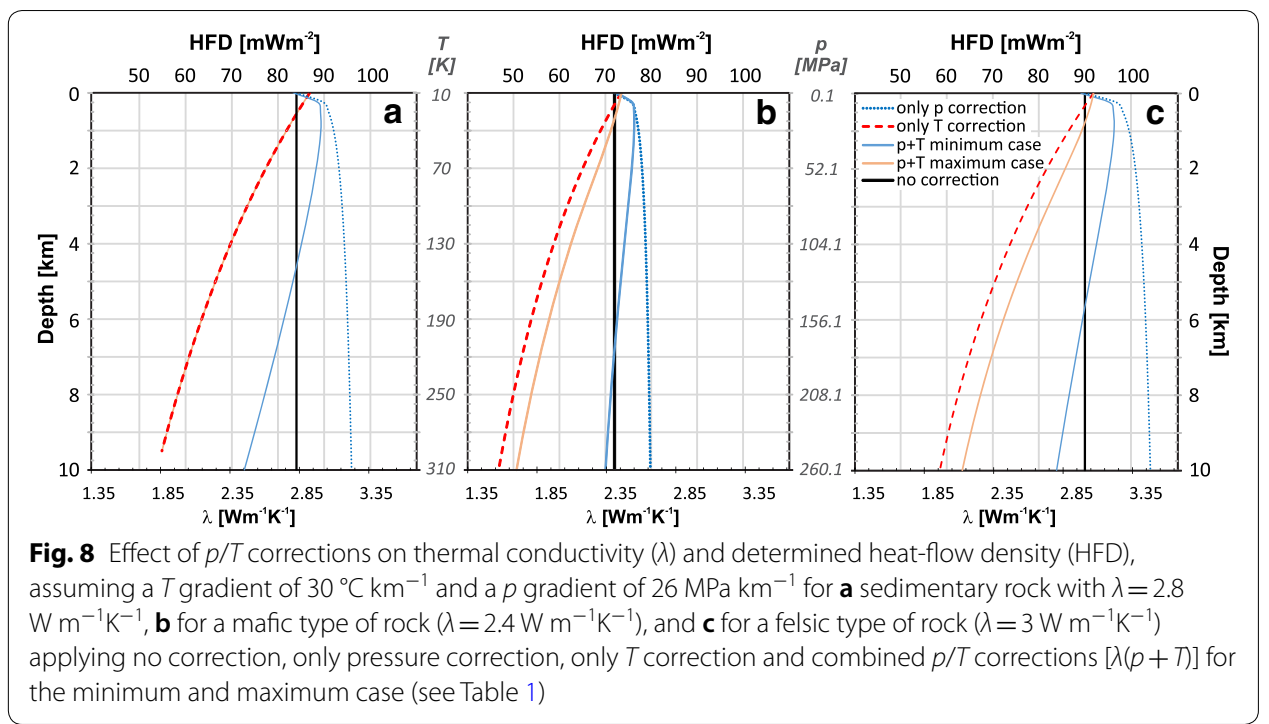

general, the higher the starting value of $\lambda_{0}$ and the deeper the considered depth (interval) are, the larger are the deviations. So, just by only considering the available $p / T$ corrections on $\lambda$, a heat flow value determined at $4 \mathrm{~km}$ depth may have an uncertainty of 10 to $>20 \%$, while the maximum uncertainty at $2-\mathrm{km}$-depth amounts to only $\sim 10 \%$, and would be even less at lower depth.

Recent studies investigating the uncertainties of $T$ in basin modeling related to thermal parameterization concentrate on unknowns in the distribution of rock thermal properties in the subsurface (the geological uncertainty of thermal properties, e.g., Elison et al. 2019). However, they did not discuss the influence of the $p / T$ correction on $\lambda$ and the resulting $T$ field. Elison et al. (2019) compare different modeling approaches for a 2-D generic model, using general T-correction approaches of Sekiguchi (1984) for matrix $\lambda$ and Zoth and Haenel (1988) for bulk $\lambda$, both uncorrelated to rock type. A $p$ correction of $\lambda$ is not discussed by the authors, but is partly considered by applying Athy's law (Athy 1930), an exponential reduction of porosity with depth that will result in an increasing bulk $\lambda$ with depth. Noack et al. (2012) investigated the sensitivity of 3-D thermal models to the selection of boundary conditions and thermal properties at a lithospheric scale. They conclude that the values of $\lambda$ implemented in their models need to be smaller than those determined on rock samples at ambient conditions, to match measured temperature profiles. However, they did not apply any of the $p / T$ corrections on $\lambda$ in their sensitivity study, which may have solved the problem. Not accounting $p / T$-dependent thermal properties may lead to wrong model calibrations and false conclusions on the relative importance of conductive versus transient conditions. The ability to assign proper thermal properties in thermal modeling is thus of outmost relevance for interpreting the subsurface thermal field and the thermal processes that define it. In this paper, we discussed heat conduction as the dominant heat transport process at a crustal scale. Transient processes due to the evolution of a sedimentary basin at different time scales (like mechanical compaction and igneous intrusions or changes of the depth of the asthenosphere) 
which are undoubtedly in operation in several sedimentary settings, are not considered. In advection-dominated heat transport settings, the conductive thermal field may be totally masked by, e.g., fluid convection. Thus, $p / T$ corrections will have a minor impact on the reservoir simulation of the temperature field of a geothermal target dominated by fluid flow processes. However, also dynamic reservoir simulations require reliable boundary conditions. For instance, constraining the basal (terrestrial) heat flow for a given depth and area requires also a sound understanding of $p / T$-dependent thermal properties.

\section{Conclusions}

Heat flow, thermal conductivity, and radiogenic heat production of rocks are the most influential parameters that affect the temperature distribution in the Earth's interior. The evidence presented in this paper shows that thermal models of the crust heavily depend on the in situ values of $\lambda$, which involves the application of $p / T$ correction functions.

To obtain reasonable simulation results of the thermal field at a lithospheric scale, the implementation of both, $p$ and $T$ corrections to $\lambda$ becomes of increasing relevance with greater depth. Consideration of the entire lithosphere system in thermal models may be advantageous, to better constrain the necessary thermal boundary conditions for small-scale thermal models of the uppermost $5 \mathrm{~km}$ of the crust being subject of energy-resources exploration.

Although the modeling performed in this study does not allow to judge on the correctness of a respective function, which is sensitive to rock type and the method of laboratory measurement, the results help to quantify the overall uncertainty of thermal (exploration) models. Advanced laboratory $\lambda$ data are mandatory, obtained on rock specimens simultaneously exposed to $p$ and $T$. An improved understanding of the involved thermal processes will support in approaching a new stage of $T$-field characterization, helping also to evaluate the uncertainty of heat-flow determinations.

\section{Supplementary information}

Supplementary information accompanies this paper at https://doi.org/10.1186/s40517-020-0157-0.

Additional file 1. Additional tables with a compilation of $p$ and $T$ correction functions available in literature.

Acknowledgements

We would like to thank two anonymous reviewers for providing helpful comments on an earlier draft of the manuscript. Especially the very critical reading of one of them helped to improve and to clarify this manuscript.

\section{Authors' contributions}

SF and BN analyzed and interpreted the available $p / T$ correction functions and BN performs the 2-D thermal modeling and was a major contributor in writing the manuscript. AF and HJF co-developed the geological concept of the modeled scenarios and their parameterization. All authors read and approved the final manuscript.

\section{Funding}

SF received funding from the European Union's Horizon 2020 research and innovation program under the Marie

Sklodowska-Curie grant agreement No. 703333.

Availability of data and materials

The datasets used and/or analyzed during this study are available from the corresponding author on request. 
Received: 10 October 2019 Accepted: 11 January 2020

Published online: 24 January 2020

\section{References}

Abdulagatov IM, Emirov SN, Abdulagatova ZZ, Askerov SY. Effect of pressure and temperature on the thermal conductivity of rocks. J Chem Eng Data. 2006;51:22-33.

Anand J, Somerton WH, Gomaa E. Predicting thermal conductivities of formations from other known properties. SPE J. 1973:13:267-72.

Athy LF. Density, porosity, and compaction of sedimentary rocks. AAPG Bull. 1930;14(1):194-200.

Balling P, Maystrenko Y, Scheck-Wenderoth M. The deep thermal field of the Glueckstadt Graben. Environ Earth Sci. 2013;70(3):3505-22.

Beck AE. Thermal properties. In: Haenel R, Rybach L, Stegena L, editors. Handbook of terrestrial heat-flow density determination. Dordrecht: Springer; 1988. p. 87-165.

Bédard K, Comeau FA, Raymond J, Malo M, Nasr M. Geothermal characterization of the St. Lawrence Lowlands Sedimentary Basin, Québec, Canada. Nat Resour Res. 2018;27(4):479-502. https://doi.org/10.1007/s11053-017-9363-2.

Békési E, Lenkey L, Limberger J, Porkoláb K, Balázs A, Bonté D, Vrijlandt M, Horváth F, Cloetingh S, van Wees JD. Subsurface temperature model of the Hungarian part of the Pannonian Basin. Glob Planet Change. 2018;171:48-64.

Blackwell DD, Steele JL. Thermal conductivity of sedimentary rocks: measurement and significance. In: Naeser ND, McCulloh TH, editors. Thermal history of sedimentary basins. New York: Springer; 1989. p. 13-36.

Blesch CJ, Kulacki FA, Christensen RN. Application of integral methods to prediction of heat transfer from a nuclear waste repository. Columbus: Open file report ONWI-495, Battelle Memorial Institute; 1983. p. 12-7. https://doi. org/10.2172/5754517.

Deming D, Chapman D. Heat flow in the Utah-Wyoming thrust belt from analysis of bottom-hole temperature data measured in oil and gas wells. J Geophys Res. 1988;93:13657-72.

Durham WB, Abey AE, Trimmer DA. Thermal conductivity, diffusivity and expansion of Avery Island salt at pressure and temperature. Livermore, California. 1980. https://digital.library.unt.edu/ark:/67531/metadc1093573/. Accessed 8 Oct 2019.

Elison P, Niederau J, Vogt C, Clauser C. Quantification of thermal conductivity uncertainty for basin modeling. AAPG Bull. 2019;103(8):1787-809.

Emirov SN, Beybalaev VD, Gadzhiev GG, Ramazanova AE, Amirova AA, Aliverdiev AA. To the description of the temperature and pressure dependences of the thermal conductivity of sandstone and ceramics. J Phys Conf Ser. 2017:891:012335. https://doi.org/10.1088/1742-6596/891/1/012335.

Förster A, Förster HJ. Crustal composition and mantle heat flow: implications from surface heat flow and radiogenic heat production in the Variscan Erzgebirge (Germany). J Geophys Res. 2000;105(B12):27917-38. https://doi. org/10.1029/2000JB900279.

Förster HJ, Förster A, Oberhänsli R, Stromeyer D. Lithospheric composition and thermal structure of the Arabian Shield in Jordan. Tectonophysics. 2010;481(1-4):29-37.

Förster A, Förster HJ, Krentz O. Exploration of the enhanced geothermal system (EGS) potential of crystalline rocks for district heating (Elbe Zone, Saxony, Germany). Int J Earth Sci. 2018;104(1):89-101.

Freymark J, Sippel J, Scheck-Wenderoth M, Bär K, Stiller M, Fritsche JG, Kracht M. The deep thermal field of the Upper Rhine Graben. Tectonophysics. 2017:694:114-29.

Fuchs S, Balling N. Improving the temperature predictions of subsurface thermal models by using high-quality input data. Part 2: a case study from the Danish-German border region. Geothermics. 2016;64:1-14.

Fuchs S, Förster A. Well-log based prediction of thermal conductivity of sedimentary successions: a case study from the North German Basin. Geophys J Int. 2014;196:291-311.

Fuchs S, Balling N, Mathiesen A. Deep basin temperature and heat-flow field in Denmark—new insights from borehole analysis and 3D geothermal modelling. Geothermics. 2020. https://doi.org/10.1016/j.geothermics.2019.101722.

Hasterok D, Chapman DS. Heat production and geotherms for continental lithosphere. Earth Planet Sci Lett. 2011;307:59-70.

Horai K, Susaki J. The effect of pressure on the thermal conductivity of silicate rocks up to 12 kbar. Phys Earth Planet Inter. 1989;55:292-305.

Hurtig E, Brugger H. Wärmeleitfähigkeitsmessungen unter einaxialem Druck. Tectonophysics. 1970;10(1-3):67-77.

Kukkonen IT, Jokinen J, Seipold U. Temperature and pressure dependencies of thermal transport properties of rocks: implications for uncertainties in thermal lithosphere models and new laboratory measurements of high-grade rocks in the central Fennoscandian Shield. Surv Geophys. 1999;20:33-59.

Lee Y, Deming D. Evaluation of thermal conductivity temperature corrections applied to terrestrial heat flow studies. J Geophys Res. 1998;103(B2):2447-54.

Lemenager A, O'Neill C, Zhang S, Morgan E. The effect of temperature-dependent thermal conductivity on the geothermal structure of the Sydney Basin. Geotherm Energy. 2018. https://doi.org/10.1186/s40517-018-0092-5.

Miranda MM, Matos CR, Rodrigues NV, Pereira AJSC, Costa JJ. Effect of temperature on the thermal conductivity of a granite with high heat production from Central Portugal. J Iber Geol. 2019;45(1):147-61.

Noack V, Cherubini Y, Scheck-Wenderoth M, Lewerenz B, Höding T, Simon A, Moeck I. Assessment of the present-day thermal field (NE German Basin)—inferences from 3D modelling. Chem Erde. 2010;70(S3):47-62.

Noack V, Scheck-Wenderoth M, Cacace M. Sensitivity of 3D thermal models to the choice of boundary conditions and thermal properties: a case study for the area of Brandenburg (NE German Basin). Environ Earth Sci. 2012;67(6):1695-711.

Norden B, Förster A, Balling N. Heat flow and lithospheric thermal regime in the Northeast German Basin. Tectonophysics. 2008:460:215-29. 
Norden B, Förster A, Behrends K, Krause K, Stecken L, Meyer R. Geological 3-D model of the larger Salzwedel area, Germany, for temperature prognosis and reservoir simulation. Environ Earth Sci. 2012;67:511-26.

Powell WG, Chapman DS, Balling N, Beck AN. Continental heat-flow density. In: Haenel R, Rybach L, Stegena L, editors. Handbook of terrestrial heat-flow density determination. Dordrecht: Kluwer Academics; 1988. p. 167-222.

Przybycin AM, Scheck-Wenderoth M, Schneider M. The 3D conductive thermal field of the North Alpine Foreland Basin: influence of the deep structure and the adjacent European Alps. Geotherm Energy. 2015;3(17):1-29.

Rühaak W, Rath V, Clauser C. Detecting thermal anomalies within the Molasse Basin, southern Germany. Hydrogeol J. 2010;18(8):1897-915.

Schatz JF, Simmons G. Thermal conductivity of Earth materials at high temperatures. J Geophys Res. 1972;77:6966-83.

Schintgen T, Förster A, Förster HJ, Norden B. Surface heat flow and lithosphere thermal structure of the Rhenohercynian Zone in the greater Luxembourg region. Geothermics. 2015a;56:93-109.

Schintgen T, Förster A, Förster HJ, Norden B. Corrigendum to "Surface heat flow and lithosphere thermal structure of the Rhenohercynian Zone in the greater Luxembourg region". Geothermics. 2015b;58:94.

Schön JH. Physical properties of rocks: fundamentals and principles of petrophysics. In: Helbig K, Teitel S, editors. Handbook of geophysical exploration: section 1, seismic exploration. Oxford: Pergamon; 1996.

Schön SJ. Chapter 9-thermal properties. In: Schön JH, editor. Handbook of petroleum exploration and production. Amsterdam: Elsevier; 2011. p. 337-72.

Schütz F, Förster HJ, Förster A. Thermal conditions of the central Sinai Microplate inferred from new surface heat-flow values and continuous borehole temperature logging in central and southern Israel. J Geodyn. 2014;76:8-24.

Seipold U. Depth dependence of thermal transport properties for typical crustal rocks. Phys Earth Planet Inter. 1992;69:299-303.

Seipold U. The variation of thermal transport properties in the Earth's crust. J Geodyn. 1995:20:145-54

Seipold U. Temperature dependence of thermal transport properties of crystalline rocks-a general law. Tectonophysics. 1998;291:161-71.

Seipold U. Der Wärmetransport in kristallinen Gesteinen unter den Bedingungen der kontinentalen Erdkruste. GeoForschungsZentrum Potsdam, Sci Techn Rep. 2001. https://doi.org/10.2312/gfz.b103-010037.

Seipold U. Investigation of the thermal transport properties of amphibolites: I. Pressure dependence. High Temp High Press. 2002;34:299-306.

Seipold U, Huenges E. Thermal properties of gneisses and amphibolites—high pressure and high temperature investigations of KTB-rock samples. Tectonophysics. 1998;291:173-8.

Sekiguchi KA. A method for determining terrestrial heat flow in oil basinal areas. Tectonophysics. 1984;103:67-79.

Somerton WH. Thermal properties and temperature-related behavior of rock/fluid systems. Amsterdam: Elsevier; 1992.

Sonibare WA, Sippel J, di Primio R, Anka Z, Scheck-Wenderoth M, Mikeš D. Present-day thermal field and MesozoicCenozoic thermal evolution of the Western Bredasdorp Basin (South Africa): an integrated 3D numerical forward modelling approach. Mar Petrol Geol. 2018;93:57-78.

Velez MI, Blessent D, Cordoba S, Lopez-Sanchez J, Raymond J, Parra-Palacio E. Geothermal potential assessment of the Nevado del Ruiz volcano based on rock thermal conductivity measurements and numerical modeling of heat transfer. J S Am Earth Sci. 2018;81:153-64.

Vosteen HD, Schellschmidt R. Influence of temperature on thermal conductivity, thermal capacity and thermal diffusivity for different types of rock. Phys Chem Earth. 2003;28:499-509.

Vosteen HD, Rath V, Schmidt-Mumm A, Clauser C. The thermal regime of the Northeastern-German Basin from 2-D inversion. Tectonophysics. 2004:386:81-95.

Zoth G, Haenel R. Thermal conductivity. In: Haenel R, Rybach L, Stegena L, editors. Handbook of terrestrial heat-flow density determination. Dordrecht: Kluwer; 1988. p. 449-66.

\section{Publisher's Note}

Springer Nature remains neutral with regard to jurisdictional claims in published maps and institutional affiliations.

\section{Submit your manuscript to a SpringerOpen ${ }^{\circ}$ journal and benefit from:}

- Convenient online submission

- Rigorous peer review

- Open access: articles freely available online

- High visibility within the field

Retaining the copyright to your article

Submit your next manuscript at $\gg$ springeropen.com 